\title{
ANOMALOUS LOCATION OF LEFT CORONARY OSTIA WITH AORTO-PULMONARY WINDOW: A CASE REPORT
}

Vikas Singarajapura Ramakrishna1, Durgaprasad Reddy Balureddy², Mayuri Srivastava ${ }^{3}$

${ }_{1}^{1}$ Senior Resident, Department of Cardiothoracic and Vascular Surgery, Vydehi Institute of Medical Sciences, Whitefield, Bangalore. 2Professor \& HOD, Department of Cardiothoracic and Vascular Surgery, Vydehi Institute of Medical Sciences, Whitefield, Bangalore. ${ }^{3}$ Assistant Professor, Department of Cardiothoracic and Vascular Surgery, Vydehi Institute of Medical Sciences, Whitefield, Bangalore.

\section{ABSTRACT}

\section{BACKGROUND}

Aorto-pulmonary window is a rare, but well-described congenital heart disease. The combination of Aorta Pulmonary Window (APW) with an anomalous origin of right coronary artery from pulmonary artery is extremely rare. But the association of anomalous location of left coronary ostia with aorto-pulmonary window is not yet reported till date. We report one such case, which was treated successfully.

\section{KEYWORDS}

Aorto-Pulmonary Window, Anomalous Coronary Artery.

HOW TO CITE THIS ARTICLE: Ramakrishna VS, Balureddy DR, Srivastava M. Anomalous location of left coronary ostia with aortopulmonary window: a case report. J. Evolution Med. Dent. Sci. 2016;5(30):1598-1599, DOI: 10.14260/jemds/2016/376

\section{INTRODUCTION}

Aorto-pulmonary window is a rare, but well-described congenital heart disease. The combination of Aorta Pulmonary Window (APW) with an anomalous origin of right coronary artery from pulmonary artery is extremely rare and only a few cases have been reported worldwide.[1,2] The association of anomalous location of left coronary ostia with aorto-pulmonary window is not yet reported till date.

\section{CASE REPORT}

A two and a half months' old male infant was admitted with a history of intermittent tachypnoea and failure to thrive since birth. Relevant investigations were done of which transthoracic echocardiogram revealed a type 2 aortopulmonary window. Hence, surgery was performed on Cardiopulmonary Bypass (CPB) with moderate hypothermia and cold-blood cardioplegic arrest after cross clamping the aorta and looping and snugging the pulmonary artery. The aorta was opened vertically at the level of AP window and the edges were retracted. A large type 2 AP window measuring $1.5 \mathrm{~cm}$ was identified close to origin of right pulmonary artery.

The left coronary ostia, which is normally at the commissural level, was not seen. Instead, it was found above the sinotubular junction close to the AP window. The AP window was repaired using a PTFE patch in such a way that the left coronary ostia was excluded from the repair. Rewarming was started, the aorta was closed, the cross clamp released and the patient was weaned off of CPB. The postoperative period was uneventful. No ECG changes were noted. The patient was extubated after $8 \mathrm{hrs}$. of ventilation. The patient was discharged on the $7^{\text {th }}$ post-operative day.

Financial or Other, Competing Interest: None.

Submission 23-02-2016, Peer Review 20-03-2016,

Acceptance 25-03-2016, Published 14-04-2016.

Corresponding Author:

Durgaprasad Reddy Balureddy,

Professor \& HOD,

Department of Cardiothoracic and Vascular Surgery,

Vydehi Institute of Medical Sciences,

No. 82, EPIP Area, Whitefield

Bangalore-66, Karnataka.

E-mail: durga2723@gmail.com

DOI: $10.14260 /$ jemds $/ 2016 / 376$

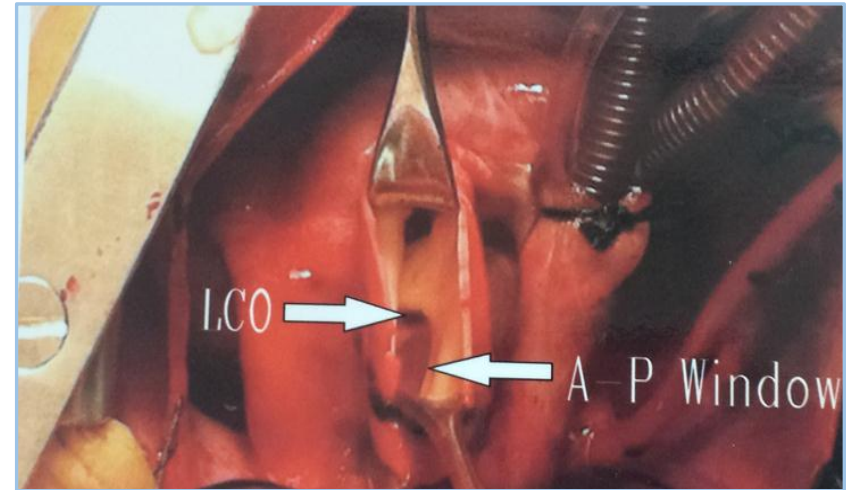

Fig. 1: Intraoperative Image of Aortopulmonary Window

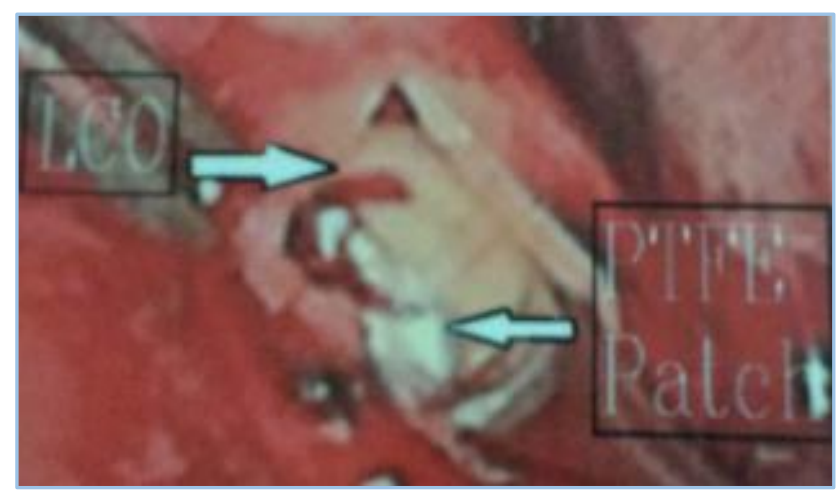

Fig. 2: PTFE Patch Closure of Aortopulmonary Window

\section{DISCUSSION}

Aorto-pulmonary window is a deficiency in the septum between the aorta and pulmonary artery resulting in a communication between the two. It appears in approximately $0.15 \%$ of all congenital cardiac diseases. ${ }^{[3]}$

It has been classified into 3 types.

\section{Type I (Proximal) Defects}

Occur in the proximal part of the aorto-pulmonary septum between the aorta and main pulmonary artery. 


\section{Type II (Distal) Defects}

Occur in the distal part of the aorto-pulmonary septum extending into right pulmonary artery.

\section{Type III Defects}

The right pulmonary artery arises from aorta.

Type I is the most common and type III is the rarest. ${ }^{[4,5]}$ Aorto-pulmonary window is frequently found as an isolated lesion, but can be associated with various other congenital cardiac anomalies. $[6,7,8]$ The most common lesions associated with APW are the following: aortic origin of the right pulmonary artery, type I interruption of the aortic arch, anomalous origin of the right coronary artery from the pulmonary artery and Tetralogy of Fallot. An APW is generally diagnosed provisionally by transthoracic echocardiography and confirmed by cardiac angiography. Cardiac angiography being an invasive procedure has certain inherent risks and at times cannot be performed. There are a few case reports of non-invasive diagnosis of an APW by CT angiography, helical CT with 3D reconstruction and MRI.

\section{CONCLUSION}

Accurate preoperative diagnosis of associated lesions is the key for an optimal surgical correction of aorto-pulmonary window.

\section{REFERENCES}

1. Soloff LA. Anomalous coronary arteries arising from the pulmonary artery. Am Heart J 1942;24(1):118-27.

2. Vlodaver Z, Neufeld HN, Edwards JE. Coronary arterial variations in the normal heart and in congenital heart disease. New York: Academic Press 1975;94-7.

3. Rowe RD. Aortopulmonary septal defect. In: Keith JD, Rowe RD, Vlad P, eds. Heart disease in infancy and childhood. New York: Mcmillan 1978;3rd ed.

4. Armer RM, Shumacker HB, Klatte EC. Origin of the right pulmonary artery from the ascending aorta. Circulation 1961;24:662-668.

5. Mori K, Ando M, Takao A, et al. Distal type of aortopulmonary window: report of 4 cases. Br Heart J 1978;40:681-689.

6. Gargiulo G, Zannini L, Albanese S, et al. Interrupted aortic arch and aorto-pulmonary window: one-stage repair in the first week of life. Ann Thorac Surg 1993;56(3):554556.

7. Rein AJ, Gotsman MS, Simcha A. Echocardiographic diagnosis of interrupted aortic arch with an aortopulmonary communication. Int $\mathrm{J}$ Cardiol 1989;24(2):238-241.

8. Tabak C, Moskowitz W, Wagner H, et al. Aorto-pulmonary window and aortic isthmic hypoplasia: operative management in newborn infants. J Thorac Cardiovasc Surg 1983;86(2):273-279. 